\title{
Updated Recommendations on Cardiovascular Prevention in 2022: An Executive Document of the Italian Society of Cardiovascular Prevention
}

\author{
Massimo Volpe ${ }^{1}\left([) \cdot\right.$ Giovanna Gallo $^{1} \cdot$ Maria Grazia Modena ${ }^{2} \cdot$ Claudio Ferri $^{3}$. Giovambattista Desideri ${ }^{3}$. \\ Giuliano Tocci ${ }^{1} \cdot$ Members of the Board of the Italian Society of Cardiovascular Prevention
}

Received: 22 December 2021 / Accepted: 31 December 2021 / Published online: 13 January 2022

(c) The Author(s) 2022, corrected publication 2022

\begin{abstract}
This executive document reflects and updates the key points of a Consensus document on Cardiovascular (CV) Prevention realized through the contribution of a number of Italian Scientific Societies and coordinated by the Italian Society of Cardiovascular Prevention (SIPREC). The aim of this executive document is to analyze and discuss the new recommendations introduced by international guidelines for the management of major CV risk factors, such as hypertension, dyslipidemias and type 2 diabetes, consisting in the identification of lower therapeutic targets, in the promotion of combination fixed drug therapies and in the introduction in routine clinical practice of new effective pharmacological classes. Moreover, the document highlights the importance of effective CV prevention strategies during the the coronavirus disease 2019 (COVID-19) outbreak which has dramatically changed the priorities and the use of available resources by the national healthcare systems and have caused a reduction of programmed follow-up visits and procedures and even of hospital admissions for severe acute pathologies. In addition, the pandemic and the consequent lockdown measures imposed have caused a widespread diffusion of unhealthy behaviors with detrimental effects on the CV system. In such a context, reinforcement of CV prevention activities may play a key role in reducing the future impact of these deleterious conditions.
\end{abstract}

Keywords Cardiovascular prevention · COVID-19 $\cdot$ High blood pressure $\cdot$ Hypercholesterolemia $\cdot$ Diabetes $\cdot$ Antiplatelet treatment $\cdot$ Obesity

\section{Introduction}

This executive document reflects and updates the key points of a Consensus document on Cardiovascular (CV) Prevention realized through the contribution of a number of Italian Scientific Societies (including the Italian Society of Cardiology [SIC], Italian Society of Diabetology (SID), Italian Society of Internal Medicine [SIMI], Italian Society of

Massimo Volpe

massimo.volpe@uniroma1.it

1 Cardiology Unit, Division of Cardiology, Department of Clinical and Molecular Medicine, Faculty of Medicine and Psychology, University of Rome Sapienza, Sant'Andrea Hospital, Rome, Italy

2 Department of Cardiology, Università degli Studi di Modena e Reggio Emilia, Policlinico di Modena, Modena, Italy

3 Department of Life, Health, and Environmental Sciences, University of L'Aquila, S. Salvatore Hospital, L'Aquila, Italy
Arterial Hypertension [SIIA], Italian Society for the Study of Atherosclerosis [SISA], Italian Society of Nephrology [SIN], Italian Society of Obesity [SIO], Italian Society of Digital Health and Telemedicine [SIT], Italian Society of Nutraceutics [SINut], Italian Association of Clinical, Preventive and Rehabilitation Cardiology (AICPR), Italian Society of Gerontology and Geriatrics [SIGG], the Mediterrean Diet Foundation [FDM]) and coordinated by the Italian Society of Cardiovascular Prevention [SIPREC], published in 2021 [1].

A previous document was published in 2018 and highlighted the need for modern and comprehensive strategies to improve $\mathrm{CV}$ prevention. This was based on the so-called "4P" approach, namely Predictive of disease precursors at an early stage; Preventive, for the early elimination of risk factors; Personalized, based on the information available for everyone; Participative, which reflects the integration of multiple professionals and technologies available today with the key involvement of patients [2]. 
The aim of this updated executive recommendations of SIPREC consensus document is to analyze and discuss the evidence of the last years, providing an integrated tool to support treating physicians in their daily clinical practice.

Over the last few years, new recommendations have been introduced by international guidelines for the management of major CV risk factors (RFs), such as hypertension [3], dyslipidemias [4] and type 2 diabetes [5], consisting in the identification of lower therapeutic targets, in the promotion of combination (fixed) drug therapies and in the introduction in routine clinical practice of new effective pharmacological classes, such as sodium-glucose cotransporter-2 inhibitors (SGLT2i) and glucagon-like-peptide-1 receptor agonists (GLP1-RA) for the treatment of diabetes and proprotein convertase subtilisin/kexin type 9 inhibitors for hypercholesterolemia, respectively.

Moreover, starting December 2019 national healthcare systems have been overwhelmed by the coronavirus disease 2019 (COVID-19), caused by the severe acute respiratory syndrome coronavirus 2 (SARS-CoV-2), which was initially reported in China and then has been spreading worldwide [6]. Indeed, the COVID-19 outbreak has dramatically changed the priorities and the use of available resources by the national healthcare systems. The pandemic and the consequent lockdown measures imposed in several countries have caused a widespread diffusion of unhealthy behaviors with detrimental effects on the CV system, including inappropriate dietary habits, sedentary lifestyle and smoking [7, 8]. Furthermore, as a consequence of the COVID-19 outbreak, screening preventive clinical programs have been halted or significantly slowed since a relevant number of programmed follow-up visits and procedures have been cancelled, and even hospital admissions for severe acute pathologies, such as myocardial infarction, have been significantly reduced, with a parallel increase in fatality and complication rates [9-11]. This represents a serious social issue, whose impact will last for many years, and which deserves priority attention by the scientific and healthcare communities. In such a context, reinforcement of $\mathrm{CV}$ prevention activities may play a key role in interrupting this vicious circle [12].

\section{CV disease: critical issues in the COVID-19 era}

As a consequence of the COVID-19 outbreak, new intensive care units and wards specifically dedicated to this critical condition have been hurriedly opened and a change of destination of entire hospitals and departments was urgently planned and established. Particularly in the first months of 2020, outpatient clinics were just interrupted for months, deleting or postponing millions of visits, procedures, surgical operations and screening or prevention programs [13].
Indeed, the general recommendation, shared by Centers for Disease Control and Prevention worldwide, was to defer any test or procedure unlikely to directly impact on clinical care or outcomes $[14,15]$. In such a context, also screening and follow-up programs have been canceled, leading to a worrying overflow of missed diagnoses and delayed specific treatments, with predictable future consequences on increased rates of morbidity and mortality with a socio-economic impact and increased burden for Healthcare Systems. Moreover, a substantial reduction of hospitalizations for acute conditions other than COVID-19, such as acute coronary syndromes or cerebrovascular accidents, due to the fear of a possible contagion in the hospital setting, has been recorded during the intial phases of the pandemic [9-11]. The deferral of interventional procedures or of specific pharmacological treatments for these conditions are likely to generate meaningful sequelae in the next years, such as an increase of heart failure incidence and hospital admissions.

In addition, clinical risk for severe COVID-19 infection correlates with both advanced age and pre-existing medical conditions. The association between $\mathrm{CV}$ disease (CVD) and poor outcomes in COVID-19 has been demonstrated to exist independent of potential confounders and the presence of CVD is a key RF for the development of CV complications of COVID-19, such as myocardial injury, myocarditis, pericarditis, heart failure, arrhythmias and venous thromboembolic events [16-19].

In this context, the best strategy is represented by an integrated approach promoting and combining population and individual preventive interventions and vaccination campaigns of general population as fundamental weapons to reduce SARS-CoV-2 infection and COVID-19 overt disease [20-22]. More than 7 billion vaccine doses have been already administered worldwide. However, a huge effort should be done by national healthcare systems to further implement vaccination strategies. In this view, we strongly recommed that subjects affected by CVD get promptly vaccinated against SARS-CoV-2 to reduce the risk of COVID-19 and the burden of potentially serious related complications.

Another field of great interest in CV prevention is represented by the implementation of novel health technologies and by an expanded coverage of telemedicine. Indeed, telemedicine and remote monitoring may allow to optimize RFs control, modulate medications, assess diets and physical activity levels and perform closer follow-up, thus representing a great opportunity to enhance patient empowerment. Particularly in the context of CVD, real-time consultation using audio/video communication technology instead of in-person visits, as well as mobile health and telemonitoring are feasible and may reinforce primary and secondary prevention practices [23-25]. Moreover, during tele-visits physicians may have the opportunity to speak with family members and caregivers, aquiring exact information about 
patients' health status, including complete medication lists (which are often forgotten during office visits). In this view, digital health may represent a fundamental innovative opportunity to improve the quality of medical care, also reinforcing patient-physician relationship and enhancing patients'awareness and self-motivation in the management of their clinical conditions, and it should be included in long-term future CVD prevention strategies [23-25].

\section{Estimation of CV risk}

The 2021 European Guidelines have introduced some new recommendations in the estimation of CV risk, both in apparently healthy people (primary prevention) and in those who have already experienced a CV event (secondary prevention) [26].

The most important novelty is represented by the use of the updated Systemic Coronary Risk Estimation 2 (SCORE2) which, differently from the previous SCORE algorithm, estimates not only 10-year risk of CVD death but also of non-fatal CVD events (such as myocardial infarction and stroke) in subjects aged between 40 and 69 years [27]. In older patients the SCORE2-OP algorithm may better reflect the total burden of MACEs [28]. A 10-year CV risk (fatal and nonfatal MACEs) is generally considered very high and treatment of CV RFs is recommended when SCORE2 is $\geq 7.5 \%$ in subjects aged $<50$ years, $\geq 10 \%$ in those aged between 50 and 69 years and $\geq 15 \%$ in older patients aged $>70$ years [26].

A 10 -year CV risk of 2.5 to $5 \%$ in subjects aged $<50$ years, 5 to $<10 \%$ in those aged $50-69$ years and 7.5 to $15 \%$ in patients aged $>70$ years is considered high and treatment of RFs should be considered, taking into account $\mathrm{CV}$ risk modifiers, frailty, polypharmacy, life-time risk, patient preferences and treatment benefit. A 10 -year CV risk $<2.5 \%$, $<5 \%$ and $<7.5 \%$ in subjects aged $<50,50-69$ and $>70$ years, respectively, is considered low-to-moderate and requires pharmacological treatment when lifestyle modification fails to control RFs and if the estimated lifetime risk and treatment benefit is considered substantial [26].

It should be also highlighted that current risk charts and scores do not take into account organ damage (OD), although it has been largely demonstrated that markers of OD, such as left ventricular hypertrophy, carotid atherosclerosis, reduced estimated glomerular filtration rate (GFR) or creatinine clearance, microalbuminuria or proteinuria, may predict CV outcomes [29]. Accordingly, it has been shown that the addition of markers of OD to traditional scores may enhance their predictive power for the incidence of major $\mathrm{CV}$ events, providing a greater performance on risk stratification. These findings support the concept that assessment of multiple sites of OD in the same patient may be of great

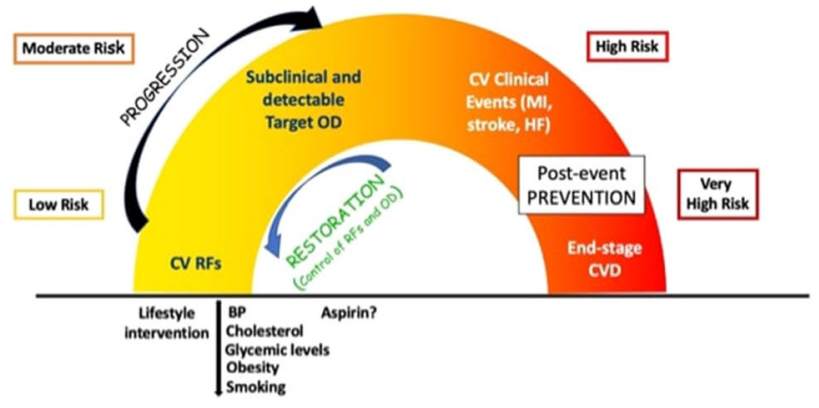

Fig. 1 Multifactorial integrated $\mathrm{CV}$ prevention strategies along the $\mathrm{CV}$ continuum. $\mathrm{CV}$ cardiovascular, $C V D$ cardiovascular disease, $H F$ heart failure, $M I$ myocardial infarction, $O D$ organ damage, $R F s$ risk factors

impact in clinical practice, in order to better identify individual global CV risk profile [30-32].

Indeed, CVD should be considered as a "continuum" from the presence of CV RFs through the development of subclinical and overt OD to the occurrence of MACEs, and preventive measures could and should be adopted at each level of the continuum to delay or even interrupt this progression. The intensity of preventive interventions and eventually of pharmacological treatments should be assessed on the basis of individual $\mathrm{CV}$ risk and as a result of a shared decision-making process [33] (Fig. 1).

New recommendations

In apparently healthy people aged $<70$ years without established CVD estimation of 10-year fatal and non-fatal CV risk with SCORE2 is recommended

In apparently healthy people aged $\geq 70$ years without established CVD, estimation of 10-year fatal and non-fatal CVD risk with SCORE2-OP is recommended.

A stepwise treatment-intensification approach aiming at intensive risk factor treatment is recommended for apparently healthy people at high or very high CV risk, as well as patients with established CVD and/or diabetes, with consideration of CV risk, treatment benefit of Rfs, risk modifiers, comorbidities, and patient preferences

Treatment of CV RFs is recommended in apparently healthy people at very high $\mathrm{CV}$ risk (SCORE2 $\geq 7.5 \%$ for age under 50 years; SCORE2 $\geq 10 \%$ for age $50-69$; years SCORE2-OP $\geq 15 \%$ for age $\geq 70$ years

Treatment of CV RFs is recommended in apparently healthy people at high CV risk (SCORE2 2.5-7.5\% for age under 50 years; SCORE2 5-10\% for age 50-69; years SCORE2-OP 7.5-15\% for age $\geq 70$ years 


\section{Therapeutic Management of High Blood Pressure}

The 2018 ESC/ESH guidelines on hypertension were relised with the aim of improving therapeutic efficacy of antihypertensive management and to improve blood pressure (BP) control as part of a comprehensive strategy of CV burden reduction[3, 34, 35]. Significant changes in BP therapeutic targets have been introduced. A goal of $<140 / 90 \mathrm{mmHg}$ is recommended in all patients. However, BP should be further lowered to BP values $<130 / 80 \mathrm{mmHg}$ in most patients, especially in those at high or very high $\mathrm{CV}$ risk, assuming that antihypertensive therapy is well tolerated. In patients aged $<65$ years, including diabetics, the systolic BP (SBP) goal is between 120 and $130 \mathrm{mmHg}$, whereas older subjects aged $>65$ years, independent from their CV risk, should reach SBP levels between 130 and $140 \mathrm{~mm} \mathrm{Hg}$. The recommended target of diastolic BP (DBP) is $<80 \mathrm{mmHg}$ for all hypertensive patients, independently of age, comorbidities, and established CVD. With regard to the initiation of treatment, pharmacological therapy should be promptly started in patients with grade 1 hypertension (SBP140-159/DBP 90-99 $\mathrm{mmHg}$ ) and at high CV risk or with signs of hypertension-mediated organ damage (HMOD). Drug treatment may be also considered in patients with high-normal BP (SBP 130-139/DBP 85-89 mmHg) when CV risk is very high because of history of previous CVD and particularly of coronary artery disease (CAD). Therapy should be immediately started in patients with grade 2 (SBP 160-179/DBP $100-109 \mathrm{mmHg})$ or $3(\mathrm{BP} \geq 180 / 110 \mathrm{mmHg}$ ) hypertension [3, 34, 35].

Another important aspect highlighted in the $2018 \mathrm{ESC} /$ ESH guidelines on hypertension is that recommended targets should be reached within 3 months from the initiation of the treatment. Since combination therapy regimens are more effective than uptitration of one antihypertensive agent (monotherapy), due to pathophysiological and pharmacological synergisms, this therapeutic strategy is now recommended as first-line therapy to achieve the recommended BP goals. Moreover, single-pill combinations (SPC) should be preferred, since they are characterized by a better tolerability profile and by greater adherence rates, compared to free combination therapies. The most recommended combinations are angiotensin receptor blockers (ARBs) or angiotensin-converting enzyme inhibitors (ACEi) with calcium channel blockers (CCBs) and/or a Thiazide/Thiazide-like type diuretic [3, 34, 35]. This represents an important change with respect to previous 2013 guidelines which suggested to start treatment with monotherapies, based on five principal drug classes (ACEi, ARBs, CCBs, Beta-Blockers and Thiazide-like diuretics), uptitrating the dose or switching to another drug class when BP control was not achieved [36].
New recommendations

In patients with grade 1 hypertension at low-moderate-risk and without evidence of hypertension-mediated organ damage (HMOD), BP-lowering pharmacological treatment is recommended if the patient remains hypertensive after a period of lifestyle intervention

In patients with high-normal BP drug treatment may be considered when their $\mathrm{CV}$ risk is very high due to established CVD, especially CAD

Prompt initiation of BP-lowering pharmacological treatment is recommended in patients with grade 2 or 3 hypertension at any level of $\mathrm{CV}$ risk, simultaneous with the initiation of lifestyle changes

The first objective of treatment should be to lower BP to $<140 / 90$ $\mathrm{mmHg}$ in all patients and to $130 / 80 \mathrm{mmHg}$ or lower in most patients

In patients aged $<65$ years SBP should be lowered o a BP range of $120-129 \mathrm{mmHg}$ in most patients and DBP to $<80 \mathrm{mmHg}$

In older patients aged $\geq 65$ years, including fit patients aged $>80$ years SBP should be targeted to a BP range of $130-139 \mathrm{mmHg}$

Therapeutic goals should be achieved within 3 months from the initiation of the treatment

Pharmacological treatment should be started with a two-drug combination, preferably in a SPC, with the exeption of frail older patients and those with grade 1 hypertension at low $\mathrm{CV}$ risk

The most recommended combinations are ACEi/ARBs with CCBs and/or a Thiazide/Thiazide-like type diuretic

\section{Therapeutic Management of Hypercholesterolemia}

Another fundamental intervention for $\mathrm{CV}$ prevention consists in the effective treatment of dyslipidaemias (mostly hypercholesterolemia), since the linear relationship between the reduction of low density lipoproteins cholesterol (LDLc) and CV risk is well established [37].

The lipid goals are part of a comprehensive CV risk reduction strategy and depend on individual $\mathrm{CV}$ risk evaluation. The 2019 European guidelines have proposed a lowering of LDL-c targets. Patients at very high CV risk should achieve a LDL-c reduction of at least $\geq 50 \%$ from baseline and a LDL-C goal of $<55 \mathrm{mg} / \mathrm{dL}$. For patients with history of CVD who experience a second vascular event within 2 years (not necessarily of the same type as the first event) while taking maximally tolerated statin-based therapy, a LDL-c goal $<40 \mathrm{mg} / \mathrm{dL}$ may be considered. Individuals at high CV risk should reach a LDL-c goal $<70 \mathrm{mg} / \mathrm{dL}$. In patients at moderate CV risk a LDL-c goal $<100 \mathrm{mg} /$ $\mathrm{dL}$ should be considered, while for low-risk individuals a goal $<116 \mathrm{mg} / \mathrm{dL}$ may be considered [4]. Among patients with diabetes or high trygliceride levels and in those with very low LDL-c levels, measurement of both ApoB and nonHDL-c is recommended as part of routine lipid analysis for risk evaluation. 
Statins with different power and at different dosages on the basis of LDL-c levels and estimated CV risk represent the first-line drug strategy. If the goals are not achieved with the maximum tolerated dose of statin monotherapy, combination therapy of statin plus ezetimibe is recommended [38]. For secondary prevention, patients at very-high risk not achieving their goal on a maximum tolerated dose of statin and ezetimibe, a combination with a PCSK9 inhibitor is recommended. PCSK-9 inhibitors are also recommended in primary prevention for patients with familial hypercholesterolemia at very-high-risk who do not achieve their goals on a maximum tolerated dose of statin and ezetimibe [39-42]. An alternative approach targeting PCSK9 consists of RNA interference. Preliminary data from phase I and II trials have shown that the small interfering RNA (siRNA) molecule inclisiran is able to reduce by up to $50 \%$ LDL-c levels with a dose-dependent effect [43].

Another potential future therapeutic perspective is represented by bempedoic acid, a first-in-class, oral small molecule which inhibits cholesterol synthesis by inhibiting the action of ATP citrate lyase, a cytosolic enzyme upstream of 3-hydroxy-3-methyl-glutaryl-coenzyme A reductase. This novel agent has been shown to reduce LDL-c levels by $30 \%$ when used in monotherapy and by about $50 \%$ in combination with ezetimibe [44-46].

With regard to hypertriglyceridaemia, statin treatment is recommended as the first drug of choice for reducing $\mathrm{CV}$ risk in high-risk individuals with triglycerides $>200 \mathrm{mg} / \mathrm{dL}$. In patients taking statins who reach LDL-c goals but have high levels of triglycerides, fenofibrate or bezafibrate may be considered [4]. In high-risk patients $n-3$ polyunsaturated fatty acid (PUFA) (icosapent ethyl $2 \mathrm{~g}$ twice in a day) may be considered in combination with a statin. However, recent trials have provided controversial results about the CV benefits of treatment with PUFA and further studies may be required [47].

New recommendations

More intensive reduction of LDL-c levels are recommended across $\mathrm{CV}$ risk categories

If the goals are not achieved with the maximum tolerated dose of statin, combination with ezetimibe is recommended

Patients at very-high risk with previous CV events, diabetes or with familial hypercholesterolemia not achieving their goal on a maximum tolerated dose of statin and ezetimibe, a combination with a PCSK9 inhibitor is recommended

\section{Therapeutic Management of Diabetes Mellitus}

Several novel recommendations have been introduced by recent guidelines also in the management of diabetes mellitus, in particular with regard to the use of new pharmacological classes with favorable CV effects namely SGLT2i and GLP1-RA [5]. Indeed, the SGLT2i empagliflozin, canagliflozin, ertugliflozin and dapagliflozin and the GLP1-RA liraglutide, semaglutide and dulaglutide have been demonstrated to reduce $\mathrm{CV}$ events in patients with diabetes and CVD, or in those who are at high or very high CV risk [48-51]. Moreover, dapagliflozin and empagliflozin have shown beneficial effects in patients with HF with reduced ejection fraction, reducing the composite of $\mathrm{CV}$ mortality and hospitalizations for HF [52, 53]. The efficacy of empagliflozin has been also shown in patients with $\mathrm{HF}$ and preserved ejection fraction [54]. The CV benefits of SGLT2i are mostly unrelated to the glucose lowering and could include effects on reducing plasma volume and direct effects on cardiac metabolism and function. GLP1RAs improve several CV parameters, including a small reduction in SBP and weight loss, and have direct vascular and cardiac effects [55].

According to this evidence, in patients with type 2 diabetes, in addition to the lifestyle intervention and metformin, SGLT2i and GLP1-RA may be used for a dual therapy, whereas sulfonylureas and acarbose are suggested only for triple therapeutic regimen. Insulin may be used at any stage of the natural history of the disease [5].

With regard to glucose control, a target HbA1c $<7.0 \%$ is recommended to reduce microvascular complications (such as retinopathy, nephropathy and autonomic neuropathy) related to diabetes and MACEs, when initiated early during the course of the disease. Less-rigorous targets should be considered in elderly patients on a personalized basis and in those with severe comorbidities or advanced CVD. In such a context, the use of new glucose-monitoring technologies such as continuous glucose monitoring and electronic ambulatory glucose in the control of postprandial glycaemia and glucose variability may contribute to a more efficacious achievement of recommended targets, although the role of these tools need be better defined [56].

In diabetic patients with high or very-high risk $\mathrm{CV}$ risk low-dose aspirin (75-100 mg/day) for primary prevention may be considered taking both ischaemic and bleeding risk into consideration, whereas it is not recommended in subjects a moderate risk.

New recommendations

Use of self-monitoring of blood glucose should be considered to facilitate optimal glycaemic control in type 2 diabetes mellitus. 


\begin{tabular}{l}
\hline New recommendations \\
\hline SGLT2i are recommended in patients with type 2 diabetes and CVD, \\
or at very high/high CV risk, to reduce CV events \\
GLP1-RA are recommended in patients with T2DM and CVD, or \\
very high/high CV risk, to reduce CV events \\
SGLT2i (empagliflozin and dapagliflozin) have demonstrated the \\
reduction of CV death and HF hospitalizations in patients with \\
HFrEF \\
Aspirin (75-100 mg/day) for primary prevention may be considered \\
in patients with diabetes at very high/high risk in the absence of \\
clear contraindication
\end{tabular}

\section{Antiplatelet Treatment}

After an acute coronary syndrome (ACS) dual antiplatelet treatment (DAPT), consisting on a potent P2Y12 receptor inhibitor combined to aspirin, is generally recommended for 12 months unless there are contraindications [57]. DAPT duration can be shortened ( $<12$ months) when haemorragic risk exceeds the risk of atherothrombotic events, and the decision depends on individual clinical judgement on the basis of the occurrence of adverse events, comorbidities and co-medications. In patients at very high risk of bleeding, defined as a recent bleeding episode in the past month or planned, not deferrable surgery in the near future, 1 month of aspirin and clopidogrel should be considered. On the other hand, in patients who have tolerated DAPT without a bleeding complication, a prolonged DAPT course $>12$ months should be considered in those with high thrombotic risk (diabetes, severe CAD, implantation of multiple stents) and without an increased risk for major or life-threatening bleeding, and may be considered in patients with moderately elevated thrombotic risk [58]. In this view, the $60 \mathrm{mg}$ bis in die (b.i.d.) dose for ticagrelor (reduced from the $90 \mathrm{mg}$ b.i.d dose recommended after ACS) is now approved in many countries for this indication [59].

More recently, data on a novel strategy of dual antithrombotic therapy (DAT), consisting of factor-Xa inhibition with a very low dose of rivaroxaban (2.5 $\mathrm{mg}$ b.i.d.) plus aspirin, has emerged as a safe treatment option for maintenance treatment beyond 12 months post ACS percutaneous coronary intervention. This strategy has demonstrated to reduce the risk of MACEs and CV mortality without a significant increase in the risk of fatal, intracranial, or critical organ bleeding events [60]. Greater absolute risk reductions have been demonstrated in high-risk patients, including those with diabetes or polyvascular disease such as CAD plus peripheral artery disease (PAD). Based on this evidence, rivaroxaban (2.5 $\mathrm{mg}$ b.i.d.) should be considered, in addition to aspirin in patients at high thrombotic risk and without an increased risk for major or life-threatening bleeding [60].
Although the recommendations for antiplatelet use in secondary prevention of atherothrombotic MACEs are clearly estabilshed, the use of aspirin in primary prevention is more controversial. Indeed, CV events are more likely to further occur in patients who have already experienced clinical manifestations of atherothrombosis [61]. However, the risk of CV events may be significantly increased also in individuals with several concomitant CV RFs. In such a context, the presence of subclinical atherosclerosis (defined as the presence of atherosclerotic plaques in the abdominal aorta, carotid arteries or iliofemoral arteries or coronary artery calcification score $(\mathrm{CACS}) \geq 1$ ), should be considered in the decision process, since it is associated with a significantly increased risk of CV events [62]. North American guidelines suggest that low-dose aspirin (75-100 mg orally daily) might be considered for the primary prevention of $\mathrm{CV}$ events among select adults aged 40 to 70 years who are at higher $\mathrm{CV}$ risk but not at increased bleeding risk [63, 64]. On the other hand, European Guidelines propose a case-by-case decision high-risk subjects, taking both ischaemic risk and bleeding risk into consideration [26].

\footnotetext{
New recommendations

Prolongation of DAPT beyond 12 months should be considered for $\leq 3$ years in patients with diabetes at very high risk who have tolerated DAPT without major bleeding complications

DAPT duration can be shortened to $<12$ months after an ACS when haemorragic risk exceeds the risk of atherothrombotic events on the basis of individual clinical judgement

Low dosages of rivaroxaban ( $2.5 \mathrm{mg}$ b.i.d.) in combination with aspirin may be used for long-term extended antithrombotic treatment in a secondary prevention setting of CAD patients with PAD

Low-dose aspirin aspirin might be considered in primary prevention in high-risk subjects taking both ischaemic risk and bleeding risk into consideration
}

\section{Obesity}

The prevalence of obesity worldwide has increased in recent decades not only among adults, but also in children and adolescents [65]. This phenomenon contributes to an increased risk of CVD, since several studies have shown that body mass index (BMI), waist-to-hip ratio and waist circumference are continuously associated with MACEs in different age categories, also after the adjustment for conventional RFs [66]. Indeed, risk-related sequalae of obesity include hypertension, dyslipidaemia, insulin resistance, systemic inflammation, a prothrombotic state, albuminuria, and the development of type 2 diabetes, heart failure and atrial fibrillation [67].

It should be considered that, although obesity is defined on the basis of BMI $>30 \mathrm{~kg} / \mathrm{m}^{2}$, this parameter is not a 
measure of fat mass and it does not convey any information on fat distribution and regional fat depots. In order to phenotype obese patients beyond BMI, the EOSS (Edmonton Obesity Staging System) has been created and stratifies the CV related to obesity on the basis of the presence and severity of concomitant RFs, physical symptoms, psychopathology or functional limitations and/or impairment of well-being [68].

With regard to the suggested therapeutic actions on the basis of waist circumference, weight reduction is recommended for values $\geq 102 \mathrm{~cm}$ in men and $\geq 88 \mathrm{~cm}$ in women. In case of waist circumference $\geq 94 \mathrm{~cm}$ in men and $\geq 80 \mathrm{~cm}$ in women, further weight gain should be highly discouraged [26].

Energy restriction is the cornerstone of weight loss, particularly when associated to physical activity. With this aim, several types of dietetic strategies may be suggested:

- Hypocaloric diets such as plant-based and hypocaloric Mediterranean diets;

- Changes to the fat and carbohydrate macronutrient composition of the diet, including low or very low carbohydrate diets, moderate carbohydrate diets, and low-fat diets $(<30 \%$ of energy from fat).

- High-protein diets to preserve lean muscle mass and enhance satiety;

- Diets focusing on specific food groups (e.g. increasing fruit and vegetables or avoiding refined sugars);

- Diets that restrict energy intake for specified time periods such as intermittent fasting or time-restricted eating.

Among the proposed strategies, the benefits of the Mediterranean diet tend to persist. Low or very low carbohydrate diets may have advantages regarding appetite control, lowering triglycerides, and reducing medications for diabetes. However, such diets may be ketogenic and should be supervised [69].

Medications approved in Europe for weight loss in obese subjects currently include the lipase inhibitor orlistat at the dosage of $120 \mathrm{mg}$, the GLP1-RA liraglutide $3 \mathrm{mg}$ administered daily or semaglutide $2.4 \mathrm{mg}$ administered weekly and the combination of naltrexone and bupropione. Recent studies with GLP1-RA (liraglutide and semaglutide) have produced positive and sustained effect of body weight reduction and metabolic impact [70]. If drug intervention is not satisfactory, bariatric surgery may be considered, representing a very effective treatment option for extreme obesity or obesity with comorbidities. In this view, a recent metaanalysis has shown that patients undergoing bariatric surgery had over $50 \%$ lower risks of all-cause, $\mathrm{CV}$, and cancer mortality compared with people of similar weight who did not have surgery [70].
New recommendations

Obesity has been recognised as a chronic disease

Obesity and overweight are associated with an increased risk of CVD

Medications for weight loss in obese subjects, including orlistat, liraglutide, semaglutide and the combination of naltrexone and bupropione may be considered when energy restriction and exercise are not sufficient

If drug intervention is not satisfactory, bariatric surgery may be considered

\section{Promotion of Healthy Dietary Habits}

In the last decades the prevalence of obesity and overweight is increasing among adults and children and the diffusion of unhealty behaviors during the COVID-19 pandemic may further contribute to this phenomenon $[71,72]$. The unregulated marketing of unhealthy products and the installation of vending machines stocked with unhealthy snacks in public venues play an important role in this context. To counteract this process, some European countries have introduced specific laws to regulate the nutritional quality of food and beverages sold in vending machines in schools. As an alternative feasible solution, until mandatory regulation is enforced it has been also proposed that all new tenders for vending machines must ensure that at least $50 \%$ of the products sold have a medium-tosmall portion size, are low in saturated fat, salt, calories, and have no added sugar, such as mineral water, unsweetened tea, low-fat milk, low fat yogurt, low fat drinking yogurt, natural fruit juices, crispbread and crackers with no saturated fat and trans fatty acids, crisps and vegetable chips that have not been fried, dried fruit and nuts (30 g packet), low-calorie fitness bars (less than 80-90 kcal), with zero cost increase to the retailer [73, 74]. Moreover, the introduction of cooling systems may allow the sell of fresh fruit, healthy sandwiches flled with salad and/or tomato and boiled ham without fat, salad and/or tomato and low-fat cheese, salad and/or tomato and turkey, tomato and tuna. This strategy, called "A vending machine for a friend", developed at National Research Council of Italy (CNR) of Rome, and with the support of the SIPREC, and the European Heart Network (EHN) is being introduced in some Italian and Lithuanian high schools and is being extended to other public workplaces [75]. This initiative will be further reinforced by the active involvement of teachers and nutrition experts through presentations, information sharing and trainings. 


\section{CV Rehabilitation and Exercise Programmes}

$\mathrm{CV}$ rehabilitation consists in a multidisciplinary intervention which includes exercise training, diet/nutritional counselling and psychosocial support. Indeed, it has been largely demonstrated that prevention and rehabilitation programmes after $\mathrm{CV}$ events reduce the recurrence of MACEs, CV hospitalizations and CV mortality and quality of life. In this view, CV rehabilitation should be started as soon as possible after a CV event and should be carried out by adequately trained health professionals [76, 77].

Exercise programmes should include aerobic and muscular resistance exercise, which should be individually prescribed based on pre-exercise screening and eventually on exercise testing. The number of sessions per week and the average duration of each session of exercise should be tailored on the basis of the $\mathrm{CV}$ risk and $\mathrm{CV}$ history of each patient $[78,79]$.

To optimize exercise training, digital and interactive decision support tools may be used, also to implement adherence. Indeed, home-based CV rehabilitation with or without telemonitoring or mobile device-based healthcare delivery through smartphones may increase participation and maintainance of long-term healthy behaviours $[79,80]$.

\footnotetext{
New recommendations

Participation in a medically supervised, structured, comprehensive, multidisciplinary rehabilitation and exercise programmes patients may improve outcomes of patients with CVD

Methods to increase exercise acitivity should be promoted, including electronic prompts or automatic referrals, structured follow-up by nurses or health professionals, and early programme initiation after discharge

Home-based cardiac rehabilitation and telehealth may be considered to increase patient participation and long-term adherence to healthy behaviours
}

\section{Conclusions}

In this updated consensus document for $\mathrm{CV}$ prevention special consideration has been given to the estimation of $\mathrm{CV}$ risk, both in apparently healthy subjects and in those affected by CVD, and to the different new recommendations introduced in the last three years for the management of the principal CV RFs, such as hypertension, dyslipidaemia and diabetes, with the aim to pursuit an integrated and multifactorial preventive strategy for reducing the burden of MACEs. In this view, interventions at both individual (physical activity, diet, control of RFs) and at at the population level (vaccination campaigns, laws to regulate the nutritional quality of food and beverages) should be promoted and should become as a fundamental part of the clinical activity of each physicians and of programmes of Healthcare Systems. This multidisciplinary approach has acquired increasing importance in the last two years in which COVID-19 pandemic has favored a widespread diffusion of behaviors with detrimental effects on the CV system and a relevant number of programmed follow-up visits and screening procedures have been cancelled with a potential increase in fatality and complication rates in the next future.

Acknowledgements We wish to thank the following authors who contributed to the paper "Prevenzione Italia 2021. Un update del Documento di consenso e raccomandazioni per la prevenzione cardiovascolare in Italia [Prevention Italy 2021-An update of the 2018 Consensus document and recommendations for the prevention of cardiovascular disease in Italy": Allegra Battistoni (Roma), Caterina Oriana Aragona (Messina), Fabio Barchiesi (Roma), Alessio Basolo (Pisa), Paolo Bellotti (Savona), Andrea Bianco (Cagliari), Claudio Borghi (Bologna), Arrigo Francesco Giuseppe Cicero (Bologna), Barbara Di Giacinto (Roma), Fredrick Fernando (Roma), Leonarda Galiuto (Roma), Davide Grassi (L’Aquila), Guido Grassi (Milano), Giancarlo Icardi (Genova), Ciro Indolfi (Catanzaro), Elisa Lodi (Modena), Maria Lorenza Muiesan (Brescia), Andrea Orsi (Genova), Stefano Palermi (Napoli), Gianfranco Parati (Milano), Andrea Passantino (Bari), Alessandra Patelli (Roma), Antonio Pelliccia (Roma), Martino Pengo (Milano), Pasquale Perrone Filardi (Napoli), Gianluca Perseghin (Milano), Roberto Pontremoli (Genova), Giuseppe Rengo (Napoli), Roberta Ricotti (Novara), Damiano Rizzoni (Brescia), Bianca Rocca (Roma), Carlo Rotella (Firenze), Guido Salvetti (Pisa), Angela Sciacqua (Catanzaro), Andrea Serdoz (Roma), Felice Sirico (Napoli), Maria Rosaria Squeo (Roma).

We wish to thank the following Scientifc Societies who shared the paper "Prevenzione Italia 2021. Un update del Documento di consenso e raccomandazioni per la prevenzione cardiovascolare in Italia [Prevention Italy 2021-An update of the 2018 Consensus document and recommendations for the prevention of cardiovascular disease in Italy": Società Italiana di Cardiologia; Società Italiana di Diabetologia; Società Italiana di Medicina Interna; Società Italiana dell'Ipertensione Arteriosa; Società Italiana per lo Studio dell'Aterosclerosi; Società Italiana di Nefrologia; Società Italiana dell'Obesità; Società per la Salute Digitale e la Telemedicina; Società Italiana di Nutraceutica; Associazione Italiana di Cardiologia Clinica, Preventiva e Riabilitativa; Istituto di Medicina e Scienza dello Sport-Sport e Salute; Società Italiana di Gerontologia e Geriatria; Consiglio Nazionale delle Ricerche; Fondazione Dieta Mediterranea; Associazione Medici Diabetologi; Fondazione Italiana Vascolare; Società Italiana di Angiologia e Patologia Vascolare; Società Italiana di Diagnostica Vascolare; Società Italiana Studio Emostasi e Trombosi, Società Italiana di Statistica Medica ed Epidemiologia Clinica.

Simonetta Bellone, Division of Pediatrics, Department of Health Sciences, Università del Piemonte Orientale, Novara, Italy. Marco Bertolotti, Division of Geriatrics, Department of Biomedical, metabolic and Neural Sciences and Center for Gerontological Evaluation and Research, Università di Modena e Reggio Emilia, Modena, Italy. Alessandro Biffi, Med-Ex, Medicine \& Exercise srl, Medical Partner Scuderia Ferrari, Rome, Italy. Agostino Consoli, Department of Medicine and Ageing Sciences and CeSI-Met, University D'Annunzio, Chieti, Italy. Alberto Corsini, Department of Pharmacological and Biomolecular Sciences, Università degli Studi di Milano, Italy; IRCCS MultiMedica, Sesto S. Giovanni, Milan, Italy. Giulio Nati, Italian Society of General Practice, Rome, Italy. Matteo Pirro, Unit of Internal Medicine, Angiology and Arteriosclerosis Diseases, Department of Medicine, University of Perugia, Perugia, Italy. Speranza Rubattu, 
Cardiology Unit, Division of Cardiology, Department of Clinical and Molecular Medicine, Faculty of Medicine and Psychology, University of Rome Sapienza, Sant'Andrea Hospital, Rome, Italy; IRCCS Neuromed, Pozzilli (IS), Italy. Bruno Trimarco, Department of Advanced Biomedical Sciences, Federico II University of Naples, Naples, Italy. Saula Vigili de Kreutzenberg, Department of Medicine, University of Padova, Padua, Italy. Roberto Volpe, National Research Council of Italy (CNR), Rome, Italy.

\section{Declarations}

Conflicts of interest The members of the Writing Committee have no conflicts of interest to discose

Open Access This article is licensed under a Creative Commons Attribution-NonCommercial 4.0 International License, which permits any non-commercial use, sharing, adaptation, distribution and reproduction in any medium or format, as long as you give appropriate credit to the original author(s) and the source, provide a link to the Creative Commons licence, and indicate if changes were made. The images or other third party material in this article are included in the article's Creative Commons licence, unless indicated otherwise in a credit line to the material. If material is not included in the article's Creative Commons licence and your intended use is not permitted by statutory regulation or exceeds the permitted use, you will need to obtain permission directly from the copyright holder. To view a copy of this licence, visit http://creativecommons.org/licenses/by-nc/4.0/.

\section{References}

1. Battistoni A, Gallo G, Aragona CO, Barchiesi F, Basolo A, Bellone S, Bellotti P, Bertolotti M, Bianco A, Biffi A, Borghi C, Cicero AFG, Consoli A, Corsini A, Desideri G, Di Giacinto B, Fernando F, Ferri C, Galiuto L, Grassi D, Grassi G, Icardi G, Indolfi C, Lodi E, Modena MG, Muiesan ML, Nati G, Orsi A, Palermi S, Parati G, Passantino A, Patelli A, Pelliccia A, Pengo M, Filardi PP, Perseghin G, Pirro M, Pontremoli R, Rengo G, Ricotti R, Rizzoni D, Rocca B, Rotella C, Rubattu S, Salvetti G, Sciacqua A, Serdoz A, Sirico F, Squeo MR, Tocci G, Trimarco B, Vigili de Kreutzenberg S, Volpe R, Volpe M, Prevenzione Italia 2021. Un update del Documento di consenso e raccomandazioni per la prevenzione cardiovascolare in Italia [Prevention Italy 2021-an update of the 2018 Consensus document and recommendations for the prevention of cardiovascular disease in Italy]. G Ital Cardiol (Rome). 2021;22(5):1-105.

2. Volpe M, Battistoni A, Gallo G, Rubattu S, Tocci G, Writing Committee; Scientific Societies. Executive summary of the 2018 joint consensus document on cardiovascular disease prevention in Italy. High Blood Press Cardiovasc Prev. 2018;25(3):327-41.

3. Williams B, Mancia G, Spiering W, Agabiti Rosei E, Azizi M, Burnier M, Clement DL, Coca A, de Simone G, Dominiczak A, Kahan T, Mahfoud F, Redon J, Ruilope L, Zanchetti A, Kerins M, Kjeldsen SE, Kreutz R, Laurent S, Lip GYH, McManus R, Narkiewicz K, Ruschitzka F, Schmieder RE, Shlyakhto E, Tsioufis C, Aboyans V, Desormais I, ESC Scientific Document Group. 2018 ESC/ESH Guidelines for the management of arterial hypertension. Eur Heart J. 2018;39(33):3021-104.

4. Mach F, Baigent C, Catapano AL, et al. ESC Scientific Document Group. 2019 ESC/EAS Guidelines for the management of dyslipidaemias: lipid modification to reduce cardiovascular risk. Eur Heart J. 2020;41:111-88.

5. Cosentino F, Grant PJ, Aboyans V, et al. ESC Scientific Document Group. 2019 ESC Guidelines on diabetes, pre-diabetes, and cardiovascular diseases developed in collaboration with the EASD. Eur Heart J. 2020;41:255-323.

6. Zhu N, Zhang D, Wang W, Li X, Yang B, Song J, et al. A novel coronavirus from patients with pneumonia in China, 2019. N Engl J Med. 2020;382(8):727-33.

7. Mattioli AV, Ballerini Puviani M, Nasi M, Farinetti A. COVID19 pandemic: the effects of quarantine on cardiovascular risk. Eur J Clin Nutr. 2020;74:852-5.

8. Kreutz R, Dobrowolski P, Prejbisz A, Algharably EAE, Bilo G, Creutzig F, Grassi G, Kotsis V, Lovic D, Lurbe E, Modesti PA, Pappaccogli M, Parati G, Persu A, Polonia J, Rajzer M, de Timary P, Weber T, Weisser B, Tsioufis K, Mancia G, Januszewicz A, European Society of Hypertension COVID-19 Task Force Review. Lifestyle, psychological, socioeconomic and environmental factors and their impact on hypertension during the coronavirus disease 2019 pandemic. J Hypertens. 2021;39(6):1077-89.

9. De Rosa S, Spaccarotella C, Basso C, et al. Società Italiana di Cardiologia and the CCU Academy Investigators Group. Reduction of hospitalizations for myocardial infarction in Italy in the COVID-19 era. Eur Heart J. 2020;41:2083-8.

10. Madjid M, Safavi-Naeini P, Solomon SD, Vardeny O. Potential effects of coronaviruses on the cardiovascular system: a review. JAMA Cardiol. 2020;5:831-40.

11. Sabatino J, De Rosa S, Di Salvo G, Indolfi C. Impact of cardiovascular risk profile on COVID-19 outcome. A meta-analysis. PLoS ONE. 2020;15:e0237131.

12. Volpe M, Gallo G. COVID-19 and the forgotten majority. High Blood Press Cardiovasc Prev. 2020;27(5):339.

13. Blumenthal D, Fowler EJ, Abrams M, Collins SR. Covid19 -implications for the health care system. N Engl J Med. 2020;383(15):1483-2148.

14. 2020 ESC guidance for the diagnosis and management of CV disease in the context of the COVID-19 pandemic.

15. Driggin E, Madhavan MV, Bikdeli B, et al. Cardiovascular considerations for patients, health care workers, and health systems during the COVID-19 pandemic. J Am Coll Cardiol. 2020;75(18):2352-71.

16. Vincent JL, Taccone FS. Understanding pathways to death in patients with COVID-19. Lancet Respir Med. 2020;8:430-2.

17. Iaccarino G, Grassi G, Borghi C, Ferri C, Salvetti M, Volpe M, SARSRAS Investigators. Age and multimorbidity predict death among COVID-19 patients: results of the SARS-RAS Study of the Italian Society of hypertension. Hypertension. 2020;76:366-72.

18. Mancusi C, Grassi G, Borghi C, Carugo S, Fallo F, Ferri C, Giannattasio C, Grassi D, Letizia C, Minuz P, et al. SARS-RAS Investigators. Determinants of healing among patients with coronavirus disease 2019: the results of the SARS-RAS study of the Italian Society of hypertension. J Hypertens. 2021;39:376-80.

19. Savoia C, Volpe M, Kreutz R. Hypertension, a moving target in COVID-19: current views and perspectives. Circ Res. 2021;128(7):1062-79.

20. Leong DP, Banerjee A, Yusuf S. COVID-19 vaccination prioritization on the basis of cardiovascular risk factors and number needed to vaccinate to prevent death. Can J Cardiol. 2021;37(7):1112-6.

21. Correia LCL, Matias D. COVID-19 vaccines: effectiveness and number needed to treat. Lancet Microbe. 2021;2(7):e281.

22. Driggin E, Maddox TM, Ferdinand KC, Kirkpatrick JN, Ky B, Morris AA, Mullen JB, Parikh SA, Philbin DM Jr, Vaduganathan M. ACC health policy statement on cardiovascular disease considerations for COVID-19 vaccine prioritization: a report of the american college of cardiology solution set oversight Committee. J Am Coll Cardiol. 2021;77(15):1938-48.

23. Monaghesh E, Hajizadeh A. The role of telehealth during COVID19 outbreak: a systematic review based on current evidence. 
BMC Public Health. 2020;20(1):1193. https://doi.org/10.1186/ s12889-020-09301-4.

24. Hollander JE, Carr BG. Virtually perfect? Telemedicine for Covid-19. N Engl J Med. 2020;382(18):1679-81.

25. Volpe M, Battistoni A, board of the Italian Society of Cardiovascular Prevention, Bellotti P, Bellone S, Bertolotti M, Biffi A, Consoli A, Corsini A, Desideri G, Ferri C, Modena MG, Nati G, Pirro M, Rubattu S, Tocci G, Trimarco B, Volpe R, de Kreutzenberg SV. Recommendations for Cardiovascular Prevention During the Sars-Cov-2 Pandemic: An Executive Document by the Board of the Italian Society of Cardiovascular Prevention. High Blood Press Cardiovasc Prev. 2020;27(5):373-7.

26. Visseren FLJ, Mach F, Smulders YM, Carballo D, Koskinas KC, Bäck M, Benetos A, Biffi A, Boavida JM, Capodanno D, Cosyns B, Crawford C, Davos CH, Desormais I, Di Angelantonio E, Franco OH, Halvorsen S, Hobbs FDR, Hollander M, Jankowska EA, Michal M, Sacco S, Sattar N, Tokgozoglu L, Tonstad S, Tsioufis KP, van Dis I, van Gelder IC, Wanner C, Williams B, ESC National Cardiac Societies; ESC Scientific Document Group. 2021 ESC Guidelines on cardiovascular disease prevention in clinical practice. Eur Heart J. 2021;42(34):3227-337.

27. SCORE2 working group and ESC Cardiovascular risk collaboration. SCORE2 risk prediction algorithms: new models to estimate 10-year risk of cardiovascular disease in Europe. Eur Heart J. 2021;42:24392454.

28. SCORE2-OP working group and ESC Cardiovascular risk collaboration. SCORE2-OP risk prediction algorithms: estimating incident cardiovascular event risk in older persons in four geographical risk regions. Eur Heart J. 2021;42:24552467.

29. Vasan RS, Short MI, Niiranen TJ, Xanthakis V, DeCarli C, Cheng S, Seshadri S, Mitchell GF. Interrelations between arterial stiffness, target organ damage, and cardiovascular disease outcomes. J Am Heart Assoc. 2019;8(14):e012141.

30. Volpe M, Battistoni A, Tocci G, Rosei EA, Catapano AL, Coppo R, del Prato S, Gentile S, Mannarino E, Novo S, Prisco D, Mancia G. Cardiovascular risk assessment beyond Systemic Coronary Risk Estimation: a role for organ damage markers. J Hypertens. 2012;30(6):1056-64.

31. Tocci G, Figliuzzi I, Presta V, Attalla El Halabieh N, Citoni B, Coluccia R, Battistoni A, Ferrucci A, Volpe M. Adding markers of organ damage to risk score models improves cardiovascular risk assessment: prospective analysis of a large cohort of adult outpatients. Int J Cardiol. 2017;248:342-8.

32. Sehestedt T, Jeppesen J, Hansen TW, Wachtell K, Ibsen H, Torp-Pedersen C, Hildebrandt P, Olsen MH. Risk prediction is improved by adding markers of subclinical organ damage to SCORE. Eur Heart J. 2010;31(7):883-91.

33. Volpe M, Erhardt LR, Williams B. Managing cardiovascular risk: the need for change. J Hum Hypertens. 2008;22(2):154-7.

34. Volpe M, Gallo G, Battistoni A, Tocci G. Implications of guidelines for hypertension management in Europe. Circ Res. 2019;124(7):972-4.

35. Volpe M, Gallo G, Battistoni A, Tocci G. Highlights of ESC/ ESH 2018 guidelines on the management of hypertension: What Every Doctor Should Know. High Blood Press Cardiovasc Prev. 2019;26(1):1-8

36. Mancia G, Fagard R, Narkiewicz K, Redon J, Zanchetti A, Böhm M, Christiaens T, Cifkova R, De Backer G, Dominiczak A, Galderisi M, Grobbee DE, Jaarsma T, Kirchhof P, Kjeldsen SE, Laurent S, Manolis AJ, Nilsson PM, Ruilope LM, Schmieder RE, Sirnes PA, Sleight P, Viigimaa M, Waeber B, Zannad F, Redon J, Dominiczak A, Narkiewicz K, Nilsson PM, Burnier M, Viigimaa M, Ambrosioni E, Caufield M, Coca A, Olsen MH, Schmieder RE, Tsioufis C, van de Borne P, Zamorano JL, Achenbach S, Baumgartner H, Bax JJ, Bueno H, Dean V, Deaton C, Erol C, Fagard R, Ferrari R, Hasdai D, Hoes AW, Kirchhof P, Knuuti
J, Kolh P, Lancellotti P, Linhart A, Nihoyannopoulos P, Piepoli MF, Ponikowski P, Sirnes PA, Tamargo JL, Tendera M, Torbicki A, Wijns W, Windecker S, Clement DL, Coca A, Gillebert TC, Tendera M, Rosei EA, Ambrosioni E, Anker SD, Bauersachs J, Hitij JB, Caulfield M, De Buyzere M, De Geest S, Derumeaux GA, Erdine S, Farsang C, Funck-Brentano C, Gerc V, Germano G, Gielen S, Haller H, Hoes AW, Jordan J, Kahan T, Komajda M, Lovic D, Mahrholdt H, Olsen MH, Ostergren J, Parati G, Perk J, Polonia J, Popescu BA, Reiner Z, Rydén L, Sirenko Y, Stanton A, Struijker-Boudier H, Tsioufis C, van de Borne P, Vlachopoulos C, Volpe M, Wood DA. 2013 ESH/ESC guidelines for the management of arterial hypertension: the Task Force for the Management of Arterial Hypertension of the European Society of Hypertension $(\mathrm{ESH})$ and of the European Society of Cardiology (ESC). Eur Heart J. 2013;34(28):2159-219.

37. Silverman MG, Ference BA, Im K, Wiviott SD, Giugliano RP, Grundy SM, Braunwald E, Sabatine MS. Association between lowering LDL-C and cardiovascular risk reduction among different therapeutic interventions: a systematic review and metaanalysis. JAMA. 2016;316(12):1289-97.

38. Cannon CP, Blazing MA, Giugliano RP, McCagg A, White JA, Theroux P, Darius H, Lewis BS, Ophuis TO, Jukema JW, De Ferrari GM, Ruzyllo W, De Lucca P, Im K, Bohula EA, Reist C, Wiviott SD, Tershakovec AM, Musliner TA, Braunwald E, Califf RM, IMPROVE-IT Investigators. Ezetimibe added to statin therapy after acute coronary syndromes. N Engl J Med. 2015;372(25):2387-97

39. Jukema JW, Szarek M, Zijlstra LE, de Silva HA, Bhatt DL, Bittner VA, Diaz R, Edelberg JM, Goodman SG, Hanotin C, Harrington RA, Karpov Y, Moryusef A, Pordy R, Prieto JC, Roe MT, White HD, Zeiher AM, Schwartz GG, Steg PG, ODYSSEY OUTCOMES Committees and Investigators. Alirocumab in patients with polyvascular disease and recent acute coronary syndrome: ODYSSEY OUTCOMES trial. J Am Coll Cardiol. 2019;74(9):1167-76.

40. Schwartz GG, Steg PG, Szarek M, et al. ODYSSEY OUTCOMES Committees and Investigators. Alirocumab and cardiovascular outcomes after acute coronary syndrome. N Engl J Med. 2018;379:2097-107.

41. Sabatine MS, Giugliano RP, Keech AC, Honarpour N, Wiviott SD, Murphy SA, Kuder JF, Wang H, Liu T, Wasserman SM, Sever PS, Pedersen TR, FOURIER Steering Committee and Investigators. Evolocumab and clinical outcomes in patients with cardiovascular disease. N Engl J Med. 2017;376(18):1713-22.

42. Karatasakis A, Danek BA, Karacsonyi J, et al. Effect of PCSK9 inhibitors on clinical outcomes in patients with hypercholesterolemia: a meta-analysis of 35 randomized controlled trials. J Am Heart Assoc. 2017;6:e006910.

43. Ray K, Stoekenbroek RM, Kallend D, et al. Effect of an RNAi therapeutic targeting PCSK9 on atherogenic lipoproteins: prespecified secondary endpoints in ORION 1. Atherosclerosis. 2018;275:e9.

44. Ballantyne CM, Laufs U, Ray KK, et al. Bempedoic acid plus ezetimibe fixed-dose combination in patients with hypercholesterolemia and high CVD risk treated with maximally tolerated statin therapy. Eur J Prev Cardiol. 2020;27:593-603.

45. Banach M, Duell PB, Gotto AM Jr, et al. Association of bempedoic acid administration with atherogenic lipid levels in phase 3 randomized clinical trials of patients with hypercholesterolemia. JAMA Cardiol. 2020;5:1-12.

46. Ray KK, Bays HE, Catapano AL, et al. CLEAR Harmony Trial. Safety and efficacy of bempedoic acid to reduce LDL cholesterol. N Engl J Med. 2019;380:1022-32.

47. Volpe M, Patrono C. The REDUCE-IT verdict on eicosapentaenoic acid and cardiovascular outcome challenged with STRENGTH. Eur Heart J. 2021;42(5):370-1. 
48. Nikolic M, Zivkovic V, Jovic JJ, et al. SGLT2 inhibitors: a focus on cardiac benefits and potential mechanisms. Heart Fail Rev. 2021. https://doi.org/10.1007/s10741-021-10079-9.

49. Del Olmo-Garcia MI, Merino-Torres JF. GLP-1 receptor agonists and cardiovascular disease in patients with type 2 diabetes. J Diabetes Res. 2018;2(2018):4020492. https://doi.org/10.1155/2018/ 4020492.

50. Volpe M, Gallo G. Cardiometabolic phenotype of heart failure with preserved ejection fraction as a target of sodium-glucose co-transporter 2 inhibitors and glucagon-like peptide receptor agonists. Cardiovasc Res. 2021;117(9):1992-4.

51. Marx N, McGuire DK. Sodium-glucose cotransporter-2 inhibition for the reduction of cardiovascular events in high-risk patients with diabetes mellitus. Eur Heart J. 2016;37:31923200.

52. McMurray JJV, Solomon SD, Inzucchi SE, Køber L, Kosiborod MN, Martinez FA, Ponikowski P, Sabatine MS, Anand IS, Bělohlávek J, Böhm M, Chiang CE, Chopra VK, de Boer RA, Desai AS, Diez M, Drozdz J, Dukát A, Ge J, Howlett JG, Katova T, Kitakaze M, Ljungman CEA, Merkely B, Nicolau JC, O’Meara E, Petrie MC, Vinh PN, Schou M, Tereshchenko S, Verma S, Held C, DeMets DL, Docherty KF, Jhund PS, Bengtsson O, Sjöstrand M, Langkilde AM, DAPA-HF Trial Committees and Investigators. Dapagliflozin in patients with heart failure and reduced ejection fraction. N Engl J Med. 2019;381(21):1995-2008.

53. Packer M, Anker SD, Butler J, Filippatos G, Pocock SJ, Carson P, Januzzi J, Verma S, Tsutsui H, Brueckmann M, Jamal W, Kimura K, Schnee J, Zeller C, Cotton D, Bocchi E, Böhm M, Choi DJ, Chopra V, Chuquiure E, Giannetti N, Janssens S, Zhang J, Gonzalez Juanatey JR, Kaul S, Brunner-La Rocca HP, Merkely B, Nicholls SJ, Perrone S, Pina I, Ponikowski P, Sattar N, Senni M, Seronde MF, Spinar J, Squire I, Taddei S, Wanner C, Zannad F, EMPEROR-Reduced Trial Investigators. Cardiovascular and renal outcomes with empagliflozin in heart failure. N Engl J Med. 2020;383(15):1413-24.

54. Anker SD, Butler J, Filippatos G, Ferreira JP, Bocchi E, Böhm M, Brunner-La Rocca HP, Choi DJ, Chopra V, Chuquiure-Valenzuela E, Giannetti N, Gomez-Mesa JE, Janssens S, Januzzi JL, Gonzalez-Juanatey JR, Merkely B, Nicholls SJ, Perrone SV, Piña IL, Ponikowski P, Senni M, Sim D, Spinar J, Squire I, Taddei S, Tsutsui H, Verma S, Vinereanu D, Zhang J, Carson P, Lam CSP, Marx N, Zeller C, Sattar N, Jamal W, Schnaidt S, Schnee JM, Brueckmann M, Pocock SJ, Zannad F, Packer M, EMPEROR-Preserved Trial Investigators. Empagliflozin in heart failure with a preserved ejection fraction. N Engl J Med. 2021;385(16):1451-61.

55. Marso SP, Daniels GH, Brown-Frandsen K, Kristensen P, Mann JF, Nauck MA, Nissen SE, Pocock S, Poulter NR, Ravn LS, Steinberg WM, Stockner M, Zinman B, Bergenstal RM, Buse JB, LEADER Steering Committee; LEADER Trial Investigators. Liraglutide and cardiovascular outcomes in type 2 diabetes. $\mathrm{N}$ Engl J Med. 2016;375:311322.

56. Beck RW, Bergenstal RM, Riddlesworth TD, et al. Validation of time in range as an outcome measure for diabetes clinical trials. Diabetes Care. 2019;42:400-5.

57. Collet JP, Thiele H, Barbato E, Barthélémy O, Bauersachs J, Bhatt DL, Dendale P, Dorobantu M, Edvardsen T, Folliguet T, Gale CP, Gilard M, Jobs A, Jüni P, Lambrinou E, Lewis BS, Mehilli J, Meliga E, Merkely B, Mueller C, Roffi M, Rutten FH, Sibbing D, Siontis GCM, ESC Scientific Document Group. 2020 ESC Guidelines for the management of acute coronary syndromes in patients presenting without persistent ST-segment elevation. Eur Heart J. 2021;42(14):1289-367.

58. Yeh RW, Secemsky EA, Kereiakes DJ, et al. DAPT Study Investigators Development and validation of a prediction rule for benefit and harm of dual antiplatelet therapy beyond 1 year after percutaneous coronary intervention. JAMA. 2016;315:1735-49.
59. Bonaca MP, Bhatt DL, Cohen M, Steg PG, Storey RF, Jensen EC, Magnani G, Bansilal S, Fish MP, Im K, Bengtsson O, Oude Ophuis T, Budaj A, Theroux P, Ruda M, Hamm C, Goto S, Spinar J, Nicolau JC, Kiss RG, Murphy SA, Wiviott SD, Held P, Braunwald E, Sabatine MS, PEGASUS-TIMI 54 Steering Committee and Investigators. Long-term use of ticagrelor in patients with prior myocardial infarction. N Engl J Med. 2015;372:17911800.

60. Eikelboom JW, Connolly SJ, Bosch J, Dagenais GR, Hart RG, Shestakovska O, Diaz R, Alings M, Lonn EM, Anand SS, Widimsky P, Hori M, Avezum A, Piegas LS, Branch KRH, Probstfield J, Bhatt DL, Zhu J, Liang Y, Maggioni AP, Lopez-Jaramillo P, O'Donnell M, Kakkar AK, Fox KAA, Parkhomenko AN, Ertl G, Störk S, Keltai M, Ryden L, Pogosova N, Dans AL, Lanas F, Commerford PJ, Torp-Pedersen C, Guzik TJ, Verhamme PB, Vinereanu D, Kim JH, Tonkin AM, Lewis BS, Felix C, Yusoff K, Steg PG, Metsarinne KP, Cook Bruns N, Misselwitz F, Chen E, Leong D, Yusuf S, COMPASS Investigators. Rivaroxaban with or without aspirin in stable cardiovascular disease. N Engl J Med. 2017;377(14):1319-30.

61. Patrono C, Morais J, Baigent C, et al. Antiplatelet agents for the treatment and prevention of coronary atherothrombosis. J Am Coll Cardiol. 2017;70:1760-76.

62. Volpe M, Battistoni A, Gallo G, Coluccia R, De Caterina R. Aspirin and the primary prevention of cardiovascular diseases: an approach based on individualized, integrated estimation of risk. High Blood Press Cardiovasc Prev. 2017;24(3):331-9.

63. Arnett DK, Blumenthal RS, Albert MA, Buroker AB, Goldberger ZD, Hahn EJ, Himmelfarb CD, Khera A, Lloyd-Jones D, McEvoy JW, Michos ED, Miedema MD, Muñoz D, Smith SC Jr, Virani SS, Williams KA Sr, Yeboah J, Ziaeian B. 2019 ACC/ AHA Guideline on the Primary Prevention of Cardiovascular Disease: A Report of the American College of Cardiology/American Heart Association Task Force on Clinical Practice Guidelines. Circulation. 2019;140(11):e596-646. https://doi.org/10.1161/ CIR.0000000000000678 (Erratum in: Circulation. 2019 Sep 10;140(11):e649-e650).

64. Bibbins-Domingo K, U.S. Preventive Services Task Force. Aspirin use for the primary prevention of cardiovascular disease and colorectal cancer: U.S. preventive services task force recommendation statement. Ann Intern Med. 2016;164(12):836-45.

65. NCD Risk Factor Collaboration (NCD-RisC). Worldwide trends in body-mass index, underweight, overweight, and obesity from 1975 to 2016: a pooled analysis of 2416 population-based measurement studies in 128.9 million children, adolescents, and adults. Lancet. 2017;390:26272642.

66. Emerging Risk Factors Collaboration, Wormser D, Kaptoge S, Di Angelantonio E, Wood AM, Pennells L, Thompson A, Sarwar N, Kizer JR, Lawlor DA, Nordestgaard BG, Ridker P, Salomaa V, Stevens J, Woodward M, Sattar N, Collins R, Thompson SG, Whitlock G, Danesh J. Separate and combined associations of body-mass index and abdominal adiposity with cardiovascular disease: collaborative analysis of 58 prospective studies. Lancet. 2011;377:10851095.

67. Chang AR, Grams ME, Ballew SH, Bilo H, Correa A, Evans M, Gutierrez OM, Hosseinpanah F, Iseki K, Kenealy T, Klein B, Kronenberg F, Lee BJ, Li Y, Miura K, Navaneethan SD, Roderick PJ, Valdivielso JM, Visseren FLJ, Zhang L, Gansevoort RT, Hallan SI, Levey AS, Matsushita K, Shalev V, Woodward M, CKD Prognosis Consortium (CKD-PC). Adiposity and risk of decline in glomerular filtration rate: meta-analysis of individual participant data in a global consortium. BMJ. 2019;364:k5301.

68. Padwal RS, Pajewski NM, Allison DB, Sharma AM. Using the Edmonton obesity staging system to predict mortality in a population-representative cohort of people with overweight and obesity. CMAJ. 2011;183(14):E1059-66. 
69. Fried M, Yumuk V, Oppert JM, Scopinaro N, Torres A, Weiner R, Yashkov Y, Frühbeck G, International Federation for Surgery of Obesity and Metabolic Disorders-European Chapter (IFSO-EC); European Association for the Study of Obesity (EASO); European Association for the Study of Obesity Obesity Management Task Force (EASO OMTF). Interdisciplinary European guidelines on metabolic and bariatric surgery. Obes Surg. 2014;24(1):42-55.

70. O'Neil PM, Birkenfeld AL, McGowan B, Mosenzon O, Pedersen SD, Wharton S, Carson CG, Jepsen CH, Kabisch M, Wilding JPH. Efficacy and safety of semaglutide compared with liraglutide and placebo for weight loss in patients with obesity: a randomised, double-blind, placebo and active controlled, dose-ranging, phase 2 trial. Lancet. 2018;392(10148):637-49.

71. US Preventive Services Task Force, Krist AH, Davidson KW, Mangione CM, Barry MJ, Cabana M, Caughey AB, Donahue K, Doubeni CA, Epling JW Jr, Kubik M, Landefeld S, Ogedegbe G, Pbert L, Silverstein M, Simon MA, Tseng CW, Wong JB. Behavioral Counseling Interventions to Promote a Healthy Diet and Physical Activity for Cardiovascular Disease Prevention in Adults With Cardiovascular Risk Factors: US Preventive Services Task Force Recommendation Statement. JAMA. 2020;324(20):2069-75.

72. O'Connor EA, Evans CV, Rushkin MC, Redmond N, Lin JS. Behavioral counseling to promote a healthy diet and physical activity for cardiovascular disease prevention in adults with cardiovascular risk factors: updated evidence report and systematic review for the US Preventive Services Task Force. JAMA. 2020;324:2076-94.

73. Van der Bend DLM, Lissner L. Differences and similarities between front-of-pack nutrition labels in Europe: a comparison of functional and visual aspects. Nutrients. 2019;11:626-41.
74. Volpe R, Maggi S. Nutrition labelling: we need a new European algorithm. ES J Nutr Health. 2020;1:1010.

75. Volpe R, Marchant S. Vending machines and cardiovascular prevention: how to implement healthy dietary habits at school. High Blood Press Cardiovasc Prev. 2020;27:417-9.

76. Bull FC, Al-Ansari SS, Biddle S, Borodulin K, Buman MP, Cardon G, Carty C, Chaput JP, Chastin S, Chou R, Dempsey PC, DiPietro L, Ekelund U, Firth J, Friedenreich CM, Garcia L, Gichu M, Jago R, Katzmarzyk PT, Lambert E, Leitzmann M, Milton K, Ortega FB, Ranasinghe C, Stamatakis E, Tiedemann A, Troiano RP, van der Ploeg HP, Wari V, Willumsen JF. World Health Organization 2020 guidelines on physical activity and sedentary behaviour. Br J Sports Med. 2020;54(24):1451-62.

77. Peretti A, Maloberti A, Garatti L, Palazzini M, Triglione N, Occhi L, Sioli S, Sun JW, Moreo A, Beretta G, Giannattasio C, Riccobono S. Functional improvement after outpatient cardiac rehabilitation in acute coronary syndrome patients is not related to improvement in left ventricular ejection fraction. High Blood Press Cardiovasc Prev. 2020;27(3):225-30.

78. Maslov PZ, Schulman A, Lavie CJ, Narula J. Personalized exercise dose prescription. Eur Heart J. 2018;39:2346-55.

79. Gevaert AB, Adams V, Bahls M, et al. Towards a personalised approach in exercise-based cardiovascular rehabilitation: how can translational research help? A "call to action" from the Section on Secondary Prevention and Cardiac Rehabilitation of the European Association of Preventive Cardiology. Eur J Prev Cardiol. 2020;27:1369-85.

80. Avila A, Claes J, Buys R, Azzawi M, Vanhees L, Cornelissen V. Home-based exercise with telemonitoring guidance in patients with coronary artery disease: Does it improve long-term physical fitness? Eur J Prev Cardiol. 2020;27(4):367-77. 